\title{
Our Ten Years Campaign against Relocation of the Komatsu-Tenmangu Shrine accompanied with Enlargement of the Kakehashi River, Japan 小松天满宮移転反対運動 10 年の歩み
}

\author{
Takeo M.s. NAKAGAWA ${ }^{*}$ Yoshifusa KITABATAKE ${ }^{*}$ \\ 中川武夫*北畠 佳 房 $^{* *}$
}

\begin{abstract}
This paper is concerned with our campain against the relocation of the Komatsu-Tenmangu shrine accompanied with enlargement of the Kakehashi river. The Komatsu-Tenmangu shrine is an important cultural property of Japan, and was constructed by Toshitsune Maeda, the third dynasty of Kaga clan in 1657. It is realized that the primary reason why it took so long time to settle down this campaign is due to the flaw of our social system. It is concluded that preservation of cultural property is not contrary to land development, and the present proposed procedures or alike must be put in practice for the real expansion of our culture. KEYWORDS: RIVER MANAGEMENT, CULTURAL PROPERTY, LAND DEVELOPMENT, FLOOD CONTROL, PUBLIC WORK, WATER EDGE, FAUNA, FLORA
\end{abstract}

\section{Introduction}

The fluvial hydro-system is sensitive to a wide range of human activities within the drainage basin. In river management, ecological and geomorphological aspects cannot be partitioned from these activities. An alluvial plain consists of forest, farm, and urban area; they provide habitats for humans as well as fauna and flora. River works must take into account the full range of these activities.

One of the greatest impacts on rivers has been the direct manipulation of water courses principally by straightening, enlargement, embankment, and dam construction. In Japan, extensive river modifications have been normally associated with flood alleviation scheme in urban areas and water-utilization. The ministry of construction (1971) has proposed the value of $1,700 \mathrm{~m}^{3} / \mathrm{s}$ (the 100 year flood) as the design-flood discharge of the Kakehashi river at Komatsu-oohashi bridge(datum point). The ministry of construction has, therefore, proposed a flood alleviation plan by construction of a total seven dams(fig.1) at the upper reache and the enlargement at the lower reache : The dams control the 100 year flood by $700 \mathrm{~m}^{3} / \mathrm{s}$, while the enlargement makes it possible to discharge the flood by $1,000 \mathrm{~m}^{3} / \mathrm{s}$ in safe. However, it became clear that only one site, Osugi, is appropriate for dam construction. Dam construction at the other sites would require the relocation of private houses of 474, and have * Kanazawa Institute of Technology 金 沢工業大学 ** Kyoto University 京都大学 


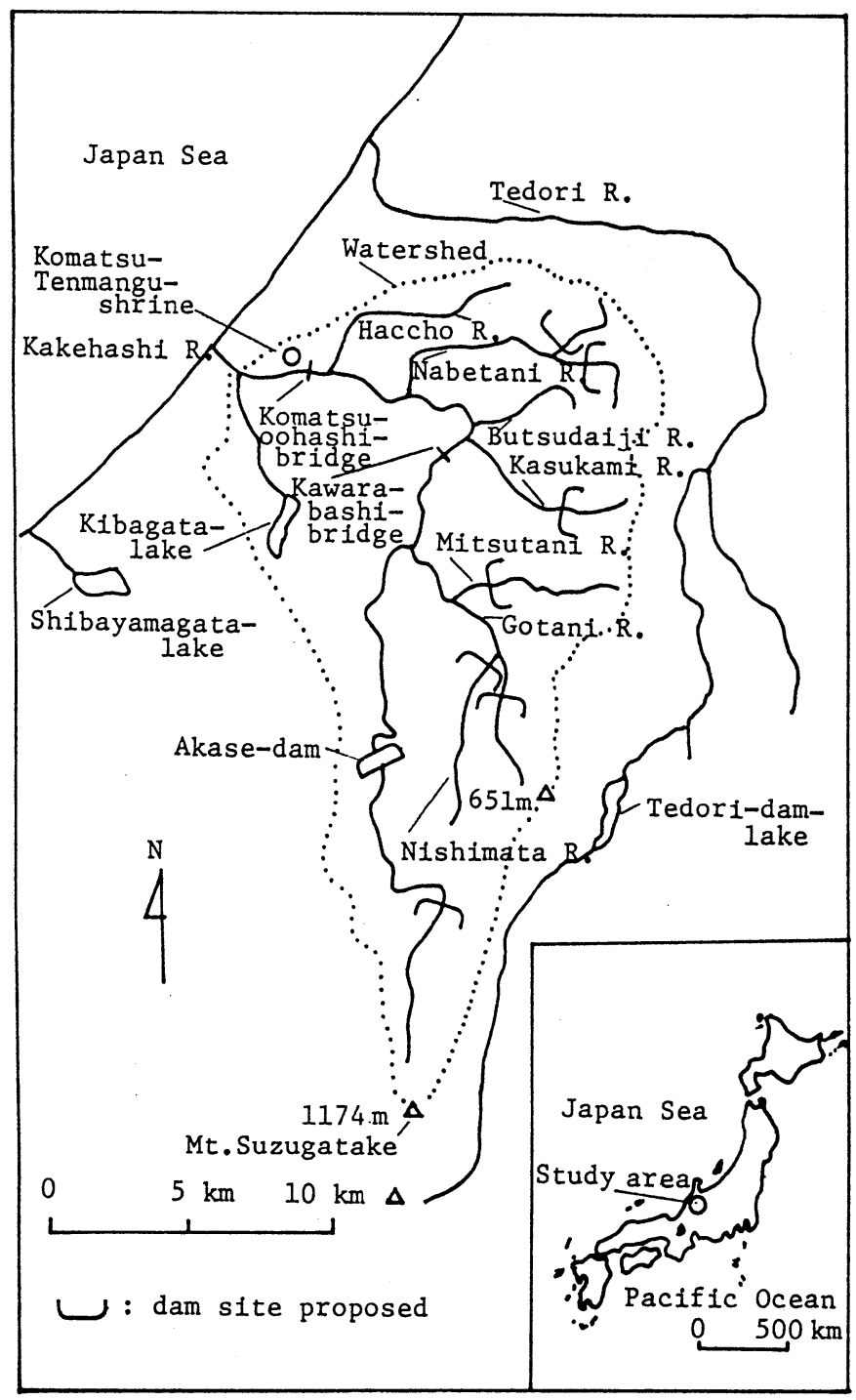

Fig.1 Map of the Kakehashi basin. The inset shows the main part of the Japanese territory.

also major consequences for shrines, temples, and other cultural properties. Thus, the dam construction to alleviate the flood is not practical at slx dam sites, viz., Gotani, Nishimata, Mitsutani, Mugiguchi, and Nabetani at least. To make matter worse, the enlargement at the lower reache results in relocation of the KomatsuTenmangu Shrine, which was founded by Toshitsune Maeda, the third dynasty of the Kaga clan:in 1657; the shrine was designated an important cultural property of Japan in 1961. Furthermore, along the lower reache there exist many private houses, shrines and temples, buried cultural properties, so that they must be preserved properly. Also, the enlargement not only alters the historical view of the urban area in Komatsu city, 


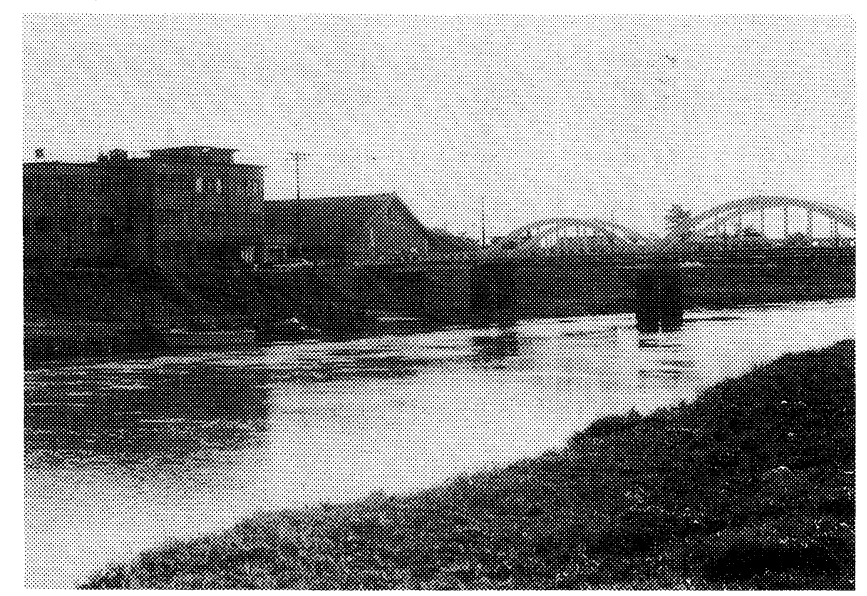

Fig.2 Beautiful water edge of the Kakehashi river and Kakehashioohashi-bridge.

but also strikes out the beautiful water's edge of the Kakehashi river(fig.2).

The flood alleviation plan proposed by the ministry of construction has caused a social dispute, but the most serious point is how to preserve the Komatsu-Tenmangu Shrine for the future generation. In this paper, a brief sketch of our ten years campaign against relocation of the Komatsu-Tenmangu Shrine will be given. Then, on the basis of this bitter experience, the necessary procedures for an ideal river management will be proposed and discussed.

2. The Kakehashi Basin

The Kakehashi basin has a total area of about $458.4 \mathrm{~km}^{2}$ (fig.1). The Kakehashi river rises in Mt. Suzugatake at an altitude of about 1,174 $\mathrm{m}$ and flows northwards to join the Gotani river, and the Kasukami river. Then, the Kakehashiriver turns to flow westwards to be joined by the Butsudaiji river, the Nabetani river, the Haccho river, the Maekawa river, finally reaching the Japan Sea. The total length of the Kakehashi river is about $42 \mathrm{~km}$.

Three-quarters of the Kakehashi basin is mountainous, and the channel slope is fairly steep in the upper reach. The slope in the upper and middle reaches is 0.1 $\tilde{\sim} 0.01$, and $0.01 \sim 0.001$, respectively. However, in the lower reach the Kakehashi river becomes a so-called tidal river: The slope is quite low and the bed is covered with silt and clay; the slope in the lower reach is 0.001 0.003 .

It is known that the Kakehashi river was a meandering river until 1911 (Nakagawa et al 1986). However, the water course in the lower reach from Kawarabashi-bridge to the river mouth has been essentially confined between embankments. Fortunately, the original ecology of the fluvial hydro-system has been well preserved because the embankments are not extensive(fig.2). 


\section{The Proposed Countermeasure}

There are four methods for alleviating floods; channel widening, dam building, diversion channel excavation, and retarding basin construction. Nakagawa(1988) proposed that the excavation of a diversion channel supported by four retarding basins located just upstream of the confluence between the Kakehashi river and the Kasukami river, and one dam at Osugi, is an optimum solution for the flood control in the Kakehashi basin; construction of the retarding basins and Osugi-dam are mainly for reducing the scale of the diversion channel. The route of the proposed diversion channel originates from the confluence between the Kakehashi river and the Nabetani river, and terminates at the point just upstream of the confluence between the Kakehashi river and the Maekawa river. A terminal point of the diversion channel at the Japan Sea was not sought because of the two reasons:(1) blocking-up the mouth of the diversion channel due to the littoral drift, and (2) dividing villages.

The solution for flood problems outlined here has several advantages over another alternative methods. First, discharges from the Nabetani river, the Haccho river, and a few drainage canals will be drained into the diversion channel, so that the region surrounded by the diversion channel and the right bank of the Kakehashi river becomes safe from floods. Moreover, the better land-drainage could improve soil quality in this region. Secondly, this proposal makes it possible to achieve flood alleviation by minimising changes of the current state of the Kakehashi river together with its historical environments if the diversion channel, retarding basins and dam are constructed adequately. This study exemplifies that in many cases options are available to achieve flood control without destroying our environmental and cultural heritage.

\section{A Brief Sketch of our Campaign}

The ministry of construction had already enlarged the lower reach of the Kakehashi river in part, following the master plan without taking into account the alternative countermeasure proposed by Nakagawa(1988). Accordingly, the historical environments along the Kakehashi river were destroyed to a large extent: The damage of private houses, shrines and temples, and buried cultural properties is enormous.

In table 1 , the history of campaign against relocation of the Komatsu-Tenmangu shrine accompanied with the enlargement of the Kakehashi river is summarized.

\section{Necessary Procedures for an Ideal River Management}

It is now clear that the main reason why took so long time to settle down this campaign is due to the flaw of social system on the river management. The most critical point may be that the ministry of construction commenced the riparian work without taking the approval from the chief priest of KTS.

In table 2, the necessary procedures for an ideal river management are summarized. The most important phase is the presentation of the probationary listof 
the Expert Investigation Committee: That is, a total numbers of the comittee members recommended by the developer must be equal to those by the administrator of cultural property. It is certainly acceptable to add any number of impartial observers to the comittee.

If the first revision of the development project is not approved by the Expert Investigation Committee, it must be revised repeatedly by the developer, until it is approved.

Table 1 The history of campaign against the relocation of the Komatsu-Tenmangu shrine accompanied with the enlargement of the Kakehashi river.

1971.4.1 The Kakehashi river was designated as the first class river.

12.27 The Kakehashi river water system construction work enforcement master plan was authorized.

1994.5.6 The chief priest of KTS asked the head of shinto shrine affairs an advice to resolve the current deadlock situation.

5.13 Three representatives of KTS visited to the director of Komatsu branch office of KCWO to hear the explanation on the doubtful reparian work at the opposit bank of KTS.

5.27 Two representatives of KTS made an appeal to the vice-director of KCWO on the riparian work. Through this meeting, it became clear that the ministry of construction has no intention to change the master plan.

6.6 The ritualist of KTS met with the mayor of Komatsu. The mayor promised to persuade the director of Hokuriku regional construction bureau, the ministry of construction, Niigata realize the flying island plan, which was originally proposed by Mr.S. Miya (Nakagawa 1990).

6.9 One rerepresentative of the agency of shinto shrine affairs visited to KTS to examine the present state of affairs of KTS.

7.25 Representatives of KTS including one local delegate met the mayor of Komatsu. The mayor promised to do his best to preserve the KomatsuTenmangu shrine at the present site.

9.5 The Komatsu-Tenmangu responsible staffs met with the representatives of Komatsu-city. In the meeting, the representatives of Komatsu-city had disclosed the rivised riparian work plan by the ministry of construction for the first time. It is realized that the revised riparian work plan is essentially same as Mr. S. Miya's flying island plan. The revised riparian work plan was accepted by the chief priest of KTS, the mayor of Komatsu, and the head of Hokuriku regional bureau, ministry of construction. Hence, this does mean that the preservation of KTS at the present site comes true. However, at the same time, the problems caused by the six dam construction and the enlargement are left for the future.

See Nakagawa \& Kitabatake(1995) for the full details of this campain.

Table 2 Necessary procedures for an ideal river management

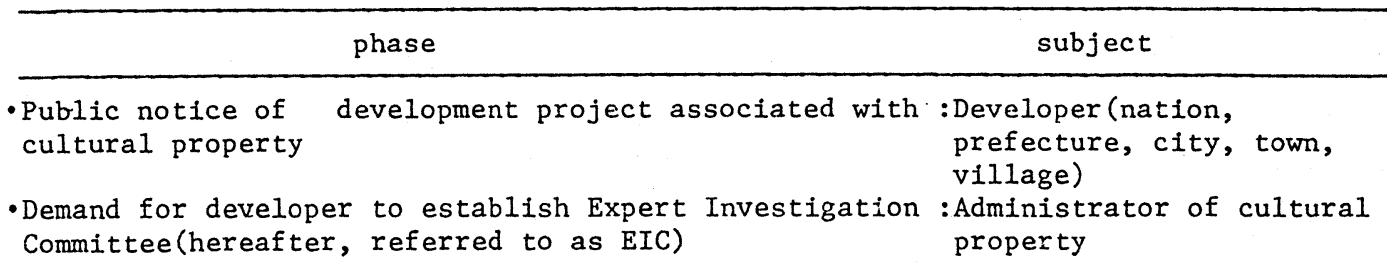


- Determination of organization of EIC

- Presentation of probationary list of committee inember candidates

- Confirmation of committee members
: Developer and administrator of cultural property :Developer and administrator of cultural property : Developer and administrator of cultural property

Refer Nakagawa \& Kitabatake(1995) for the more detail.

6. Conclusion

There may be no argument that the corruption of the public works in Japan is mainly caused by the one-sided decision making procudeure: The decision making is solely made by the developer, who glues together politicians and construction companies. As the result, today no public works are conducted for the majority in Japan, but for the minority including politicians and workers in construction companies, who are primarily interested in their own profit. It seems that even the public workers donot contribute to any happiness of our society. Take for example, we are deeply plunged into the cultural crisis, for uncountable cultural properties are destroyed by unwanted public works day by day.

It is believed that preservation of cultural property is not contrary to land development, but both of them are indispensable for the real expansion of our culture. If we fail to harmonize the preservation of cultural property with the land development, it might happen not only to deprive the vindication of our ancestor's life, but also to make our own life empty. It is, therefore, essential for us all to do our best to put the present proposed procedures for an ideal river management or alike in practice in future development projects.

\section{References}

Japan Ministry of Construction, River Bureau, 1971 The Kakehashi River Water System Construction Work Enforcement Waster Plan, December(in Japanese)。

Kuroiwa, S. 1987 On the foundation of the Komatsu-Tenmangu shrine-a view from the doxy of negative and positive, and five natural elements, viz. fire, earth, metal, wood, and water. News of the Komatsu-Tenmangu Shrine, No.2, 1-9.

Nakagawa, T., Takase, N., Nakayama, S., Shirosaki, Y., Sekido, S., Tanaka, T., Chii, A., Ogura, M., Kitano, K., Tanamachi, T., Yagasaki, T. 1986 Kaga KomatsuTenmangu to Kakehashigawa, The Expert Investigation Committee of the KomatsuTenmangu Shrine and the Kakehashi River(in Japanese).

Nakagawa, T. 1988 A flood alleviation of the Kakehashi basin, Japan. Regulated Rivers, 2, 187-193.

Nakagawa, T. 1990 The Komatsu-Tenmangu and the Kakehashi river. News of the Komatsu-Tenmangu Shrine, No.6, 8-13 (in Japanese).

Nakagawa, T., Kitabatake, T. 1995 Our twenty-five years campaign against relocation of the Komatsu-Tenmangu shrine accompanied with the enlargement of the Kakehashi river, Japan. Regulated Rivers (submitted for publication). 